\title{
The Issues and Reform Suggestions of the Current Military College Physical Education Contents System Setting
}

\author{
Yan Chen \\ Army Academy of Amored Forces,Beijing ,China \\ chenyan@126.com
}

Keywords: Military sports; Curriculum content; System setup; Reform

\begin{abstract}
With the transformation of the training target of military colleges and universities, the reform of the sports curriculum content system of military colleges and universities has made some progress, but there are still some problems. These problems are mainly manifested in: monotonous content setting, lack of flexibility and attractiveness, lack of attention to professional quality requirements, too competitive, neglect of lifelong physical education and training habits, and neglecting the imparting of theoretical knowledge. The solution of these problems should be based on the needs of adapting to the training objectives of military colleges and universities, based on the characteristics of students' physical and mental development and the mastery and improvement of students' sports skills, actively renewing curriculum content, strengthening the teaching of knowledge, adding elective courses, and improving the flexibility of the curriculum so as to improve the teaching of the course. To adapt to the requirements of military personnel in the new situation.
\end{abstract}

\section{Introduction}

Under the guidance of the target of the strong army in the new era, the military colleges and universities should focus on the goal of the strong army, with a view to the mission of fighting and winning the war, and the role of military sports is becoming more and more important. With the tran sformation of talent training objectives in our military colleges and universities, most colleges and universities have been transformed from training technical officers to the primary commanding officer training "technical cooperation one". The function and mission of the colleges and universities are more prominent, which also brings great opportunities for the development of military sports courses. Military sports, as a compulsory course for students in military academies, is becoming more and more prominent with the transformation of colleges and universities. In the face of the changing changes in the military field, the military sports, which is a part of the military struggle, should grasp the times, keep pace with the times and actively renew the content of the course teaching. It is an urgent problem for all military sports workers to rebuild the content system of physical education curriculum in military academies.

\section{Problems of Physical Education Curriculum in Military Colleges and Universities}

Since the latest College meeting, various military colleges and universities actively carry out physical education curriculum according to the teaching practice of their respective schools and the characteristics of their students, optimize the allocation of curriculum resources, and set up some pertinent military sports courses, such as Chinese martial arts, military combat, $400 \mathrm{~m}$ obstacles, high wall climbing, swimming and swimming, and $5 \mathrm{~km}$ Carry out the courses of cross-country, military sports theory and so on. However, there are still many problems in the physical education curriculum in military colleges and universities, which seriously affect the physical quality of the students in military colleges and universities. There is still a gap between the requirements of the new military training and assessment outline and the physical quality requirements of the military physical fitness training standard. Specifically, physical education curriculum mainly has the following problems: 
The teaching content does not pay enough attention to the professional quality, so it is too competitive. In order to adapt to the special tasks of the army, students of military academies have higher demand for special physical development than those of ordinary college students. Due to the limited source of sports teachers in military academies, relatively weak scientific research ability, poor scientific research atmosphere and lack of scientific research funds, the scientific research results are relatively few. The teaching of military physical education curriculum can only rely on and draw on the achievements of sports scientific research in ordinary colleges and universities to enrich and promote the needs of their own curriculum development, and lack professional teachers and specialties. In this way, it is easy to ignore the particularity of the military physical education curriculum, which leads to the good interaction between teaching and learning, and the practical function of the military physical education curriculum is greatly restricted.

Teaching content neglects lifelong sports consciousness and training habits. The ultimate goal of most college students to receive physical education and physical exercise is to enhance their physical fitness and improve their health, and lay a good foundation for lifelong physical education. The task of physical education teaching in military colleges and universities is dual. On the one hand, the students should master certain fitness knowledge and methods through the teaching of physical education, and meet the needs of the students to keep healthy during the period of school. On the other hand, it should be based on the professional readiness of the cadets and the majority of students in the final study of their life. The characteristics of the study phase, to provide students with their interesting and optional course content, through physical education to promote the students to master the one or two sports skills. It is obvious that in order to meet the needs of the two aspects of the students, the content of the physical education curriculum must have the practical function of fitness and cultivate the students' lifelong physical education consciousness and exercise habits. However, there are serious deficiencies in the contents of the current physical education curriculum in military academies.

Teaching content neglects the imparting of theoretical knowledge.Sports education is also a science. The complete teaching system of sports is composed of two parts: sports theory and sports practice. It is only regarded as a simple exercise training, ignores the imparting and explanation of theoretical knowledge. It is a misunderstanding and disparage to sports science, and is also a lack of understanding of the students' learning and thinking habits. The actual effect of the students' sports practice and the long-term need to guide the corresponding sports theory, using the known to explore the unknown, so it is very important to attach importance to the imparting of sports theory knowledge. The course of military sports theory can be explained by thorough movement principle and the analysis of human movement skills, so that students can grasp the exercise function of all kinds of sports, combine their own physical quality and professional post requirements, arrange their own exercise plan rationally, develop physical ability and skills scientifically, and cultivate various qualities. Through the teaching of theoretical knowledge to let students understand the overall function of military sports and better understand the deeper meaning of military sports, students can pay more attention to military sports training, and at the same time, more targeted training in relevant subjects.

\section{Optimize the Curriculum and Train Qualified Military Personnel}

In order to make the military physical education adapt to the needs of the military construction in the new period and the local war under the high technology conditions, the military personnel should be trained to adapt to the military personnel. In accordance with the education regulations of the Chinese people's Liberation Army, the theme of training the soldiers in science and technology is deepened, and the training content, standards, methods and management of the overall optimization are formed. System. Optimize the previous military physical education curriculum, and build a scientific, reasonable, maneuverable and targeted military physical education curriculum.

Updating the content of the course to improve the quality of the students.In order to cultivate qualified military personnel in the new period, it is necessary to expand the train of thought of physical education, update the contents of the military body in time and improve the comprehensive 
quality of the students in accordance with the requirements of the military training and assessment outline and the standards for physical exercise of military personnel. First, to cultivate their military consciousness, improve their military quality and combat spirit, we must add some physical training projects with combat characteristics, highlight practical courses, innovate practical courses and training contents, simulate the battlefield environment, and highlight the battlefield environment. Under the conditions of chemical warfare, special operations, and information-based operations, the training courses for sea crossing, such as anti vertigo, high altitude anti anoxia, etc. The two is that the content of the curriculum should reflect the nature of the times. We should closely follow the needs of the army's fighting capacity construction and military struggle, explore the new way of integrating with the integrated training of the troops, and use the latest achievements of the integration training of troops to draw the innovative development of the course teaching and training, make the course content close to the task of the army, close the practice of the science and technology, and vigorously build the Department of winning the information war. The research system, curriculum system, teaching system and content updating mechanism make military physical education unified with winning the future war. In addition, the choice of physical education curriculum content should give full consideration to the cultivation of students' sound personality and the socialization of students under the premise of fully developing their personality. The content of mental health education should also be actively absorbed into the physical education curriculum, such as sports physiology, sports health care, sports injury treatment and other aspects of health education is the content of health education, to increase these content, can improve the students' health awareness.

Strengthening the teaching of sports knowledge and improving the humanistic quality.Sports knowledge teaching is very important for helping students form long-term and sustainable physical exercise habits. Nowadays, the education of military colleges and universities has gradually developed to the direction of the combination of post - post education and educational education. Post - service education institutions will become the main body of military college education. In the face of this new situation, new task and new requirement, the military academies should increase the teaching of theoretical knowledge of sports, because "post education is a kind of vocational education, and has distinctive professional characteristics of military sports." The trainees should be educated in the field of military sports. They must master the relevant theoretical knowledge and specialized skills of military sports and integrate learning, work and research into one. "On the basis of making the students master the basic theory of military sports major, the ability to cultivate and solve practical problems in the field of post job should be emphasized." "Trainees have comprehensive qualities, which are embodied in the unity of knowledge and ability, theory and practice".

At the same time, sports belongs to the category of human culture. As an important aspect of human social history and culture, military sports should play an active role in the humanistic quality education of military personnel. Military sports also unconsciously deviate from the technical level. Military sports, as an important aspect of cultural carrier, have profound connotation in this aspect, such as military sports history, military sports ethics, military sports sociology and so on, which can expand the military humanistic quality education and provide broad space so that it can be closer to the essence of military sports culture and education.

Setting up elective courses and activity courses to improve the flexibility of courses. The future development direction of military physical education is from physical fitness to fitness, entertainment, interest and so on. The type of physical education curriculum in military colleges and universities is the hot spot of teaching reform in recent years. Under the guidance of the reform of military colleges and universities in the new period of the Central Military Commission, various schools have designed a variety of classes, such as basic class, physical ability class, option class, interest class, etc. These classes are based on the teaching content and the purpose and tasks of the course, and to a large extent meet the requirements of training military talents in the new era. At present, there are two types of senior high school autonomous activity classes and open comprehensive courses. In the independent activity class, the quality class and the competition activity class are usually treated as invisible courses. In addition to offering special lectures, technical tutorship 
and examination test, the teacher mainly consists of students' independent activities, self-study and training, organizing and training competitions, and observing and communicating. The teaching course of the club system or the association system in the open comprehensive course is different from the traditional traditional teaching course, but also different from the independent activity class. It is open in the teaching management and allows the students to organize their own competition activities in the school. Therefore, the military colleges and universities have a positive change of concept in the physical education curriculum. In order to improve the flexibility and autonomy of the curriculum, the traditional military physical education class has been broken, and some curriculum types which are popular and promising are actively added.

\section{Conclusion}

Of course, the above-mentioned countermeasures and suggestions are not applicable to all military academies, but only the general idea and the guiding principles of principle. The colleges and universities should develop their respective training functions and actively set up pertinent physical education courses to improve the quality of the training of military personnel. In addition, the curriculum reform should not be "temporary", and should be carried out step by step on the basis of a pilot project. It will not be effective overnight. In the process of implementation, it is sure that there will be great difficulties and challenges in the process of implementation. Strong support from up and down.

\section{References}

[1] X.N.Wu. Research on the Functions of Military Sports in the New Era[J].JOURNAL OF PLA INSTITUTE OF PHYSICAL EDUCATION, 2001, (2): 45.

[2] B.Z.Li,Z.Zhang,X.Y.Wang. Discussion on the Curriculum Setting of Military Physical Education in Military Post-education Colleges[J].JOURNAL OF PLA INSTITUTE OF PHYSICAL EDUCATION, 2007, (3): 118 .

[3] T.Liu,Y.L.Ning,X.S.Song .The analysis and Enlightenment of Sports Curriculum in the United States Air Force Academy[J].Course Education Research,2017, 23.

[4] G.H.Zhou ， X.Y.Lv.THE EXCEPTIONAL IDEA SCHOOL IN AMERICA AND ITS IMPLICATION FOR THE EDUCATIONAL REFORM OF CHINA[J].STUDIES IN FOREIGN EDUCATION,2007, 9.

[5] Q.L.Zeng,Z.J.Qin ,H.W.Zhang.The Idea and Enlightenment of Sports Education in the United States Air Force Academy[J].Journal of Military Physical Education and Sports, 2016, 2.

[6] J.L.Liao , Y.C.Han.The Characteristics and Enlightenment of Sports Curriculum in the United States Air Force Academy[J].Journal of PLA Institute of Physical Education, 2011, 3.

[7] Jesse Mala,Tunde K. Szivak,William J. Kraemer.Improving Performance of Heavy Load Carriage During High-Intensity Combat-Related Tasks[J] . Strength and Conditioning Journal . 2015 (4). 